\title{
Does employment in high risk professions relating to firefighters and emergency workers cause injuries that requires long hospitalization?
}

\author{
Hrvoje Lalić, Iva Kruljac \\ Medical School University, Rijeka, Croatia \\ Correspondence: Hrvoje Lalić. MD, Ph D, Professor. Address: Brentinijeva 5, 51000 Rijeka, Croatia. E-mail: \\ hlalic@inet.hr \\ Received: May 30, 2013 \\ Accepted: October 9, 2013 \\ Online Published: October 18, 2013 \\ DOI: $10.5430 /$ jha.v3n2p1 \\ URL: http://dx.doi.org/10.5430/jha.v3n2p1
}

\begin{abstract}
Firefighters and emergency workers are exposed to increased injury risks. The objective of the paper was to find out if such activities cause injuries that require long hospitalization. The files of 137 firefighters in Littoral Mountainous County, Croatia, were examined as well as those of 120 emergency workers in the last decade. The results have shown that on average firefighters were treated in hospitals 1.33 days, and emergency workers 0.018 days, $p=.019, p<.05$. The firefighters' sick leave was longer, with a mean 63.91 days compared to emergency workers sick leave mean 22.90 days, but if two firefighters on long sick leave were excluded, the difference between two groups was not significant, $p=.256$, $p>.05$. While these injuries result in short hospitalizations time the sick leave time takes longer and requires extensive outpatient physical therapy that burden hospital system. Overall, the amount of medical care time to return these injured workers to duty is large, there is necessity of implementing innovative injury prevention programs.
\end{abstract}

\section{Key words}

Firefighters, Emergency workers, Injuries, Hospital treatment

\section{Introduction}

When firefighting as a profession is mentioned one immediately thinks of a well trained person that is professionally educated, technically equiped and promptly ready to face the most serious situations which endanger people's lives and assets ${ }^{[1]}$. Such a person must be physically and mentally stable. They are checked up by a number of psychological tests like PSS Cohen Stress Perception Scale, COPE questionnaire, STAI X1 and STAI X2 anxiety tests and Beck Depression Inventory etc. ${ }^{[2]}$. In such tests firefighters are exposed to show mean values above those of general population.

Physical fitness is of a great importance for firefighting like a dangerous profession with high injury rates, particularly musculoskeletal ${ }^{[3]}$. Every discrepancy of regular body status, such as obesity with obese BMI $>30 \mathrm{~kg} / \mathrm{m}^{2}$, leads firefighters to experience a musculoskeletal injury 5.2 times over their fit colleagues.

Firefighters due to their biomechanically and energetically demanding activities have more knee and ankle complaints, and disabilities resulting from back complaints in the relation to office workers ${ }^{[4]}$. Slips, trips and falls are most common types of injury among firefighters ${ }^{[5]}$. 
Traditionally, firefighting profession is connected with fire extinction so probable injuries could be body burns of various degrees ${ }^{[6]}$. Today, firefighters are engaged in many risky jobs such as saving people from ruins after natural disasters, rescuing the drowned, preventing suicide attempts, rescuing victims from accidents and other hazardous situations. Therefore different other injuries may be expected in firefighters besides burns.

In Croatia, a hired firefighter in service i.e. a professional firefighter, must be of age, adequately educated, with a least secondary or higher technical qualification. Firefighting is a job done under specific working conditions and all requirements considering employing and engaging them in the field have to be met.

Despite regulated working conditions and requirements, tragic events also occur. On the Kornati Islands, Croatia in August 2007, twelve firefighters died in an eruptive fire while one survived with lasting consequences ${ }^{[7]}$. Of thirteen firemen, two were under - aged, both 17 , and one was a recruit serving civilian military service.

Besides burns, firefighters often suffer severe injuries due to falls, equipment and machinery they use ${ }^{[8]}$. Inhalation of various smokes, dusts, harmful mixtures, gases, such as $\mathrm{CO}$, can be very dangerous ${ }^{[9]}$. There are sometimes accidents when firemen hurry to the place of intervention ${ }^{[10]}$. However, it is mostly emergency workers that are prone to traffic accidents in their daily jobs.

Transportation - related injuries are frequently classified as "multiple traumatic injuries". Such injuries in emergency medical technicians and paramedics are three times higher than in other occupations ${ }^{[11]}$.

Biauricular hearing impairment has been described in firefighters due to exposure to the noise of sirens, motor water pumps and transportation by heavy vehicles ${ }^{[12]}$. Hearing damage can be expected also in emergency workers as they often ride in siren blasting ambulances.

Medical workers are sometimes exposed to all kinds of violence, from verbal to physical, by patients and their attendants ${ }^{[13]}$. Medical workers are said to be exposed to violence to the extent larger than in any other field of work in any industry ${ }^{[14]}$. Also, healthcare workers are injured by sharp instruments, mostly needles, which increase the risk of transmitting more than 20 pathogens including hepatitis, HIV virus, malaria, syphilis, tuberculosis etc. ${ }^{[15]}$.

It was found out, that occupational fatality rate for emergency workers exceeds that of the general population and is comparable with that of other emergency public service workers ${ }^{[16]}$. Besides mentioned, sprains and strains are the leading injury ${ }^{[17]}$. The most common challengers are overexertion, falls and transport-related events ${ }^{[18]}$.

In Rijeka, Croatia, emergency workers are employees of the Croatian Institute for Emergency Medicine. Their operativeness is on the open field primarily. There are intentions to relieve their daily services by family physicians taking in charge part of emergency workers' duties.

It is primarily anticipated during family physicians shift, from 7.00 a.m. to 7 p.m. Family physician teams cover and open terrain during their daily shifts, i.e. they solve part of urgent cases on terrain. There are many adversaries to that organizational proposal due to the weak family physicians' technical equipment as well as their insufficient knowledge in the domain of urgent medicine.

The objective of this research was to find out whether high risk professions as firefighting and emergency workers result in injuries that require long hospitalization. It was also intended to suggest preventive measures to avoid or at least decrease injuries and to lessen financial burden. 


\section{Examinees and methods}

\subsection{Examinees}

The data have been collected on two occupational localities:

Occupational safety of Professional Fire Brigade Rijeka, Littoral Mountainous County, Croatia, and Occupational safety of Emergency Medicine Institute Rijeka, Littoral Mountainous County, Croatia.

The monitored period for both groups was 10 years, from the year 2002 to 2012 .

Of 132 professional firefighters during the last decade 51 were injured.

Firefighters were mean aged 36.09 years (24-57 range), and they had a total of 12.23 (1-26 range) years of employment.

Their average sick leave was 63.31 days (5-665 range), of which they spent in hospital the mean of 1.33 days (0-23 range).

The second group consisted of 120 emergency workers of whom 54 had injuries in the last 10 years.

Emergency workers (nurses or medical technicians and physicians) were mean aged 42.85 years (25-58 range), and the average employment was 14.85 (1-32 range) years.

Their mean sick leave was 22.90 (0-60 range) days, and they spent in hospital mean $0.018(0-1)$ days.

\subsection{Methods}

StatSoft, Statistics 6 program was used for data processing and creating figures (Mean Plot, Correlation matrices).

\section{Results}

The results have shown that on average firefighters were treated in hospital 1.33 days, and emergency workers 0.018 days. Statistically they differed considerably, $p=.019, p<.05$ (see Figure 1).

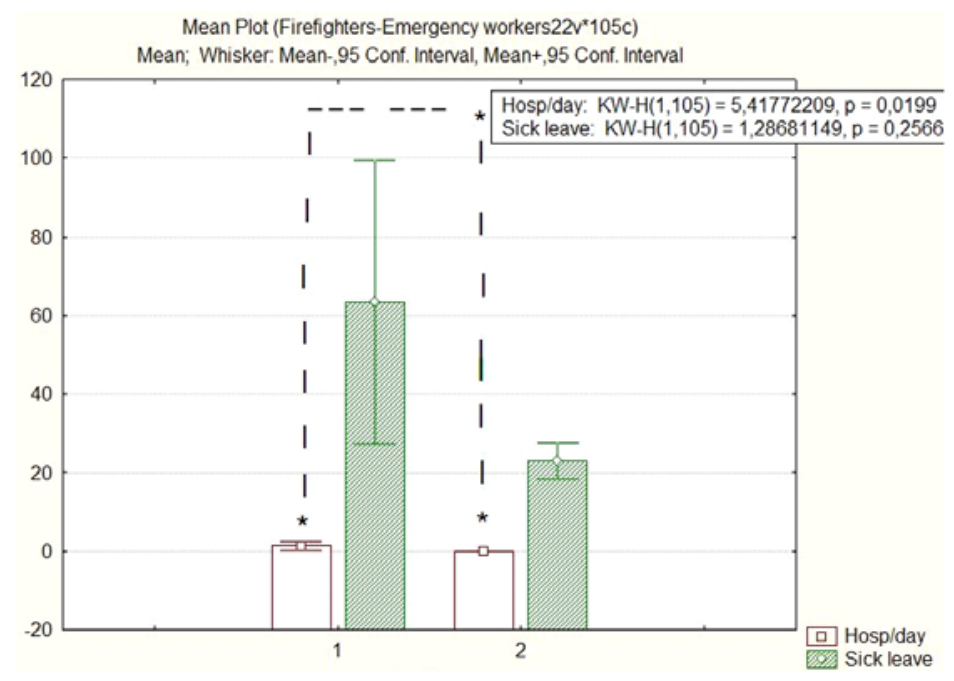

Figure 1. Relation between firefighters and Emergency workers

Firefighters' sick leave was somewhat longer, 63.31 days on average compared to emergency workers averaged 22.90 days (see Table 1, Table 2). 
Table 1. Firefighters

\begin{tabular}{lllll}
\hline No & Age & Years of employment & Sick leave & Days spent in hospital \\
\hline & (Mean) & (Mean) & $($ Mean $)$ & $($ Mean) \\
51 & 36.09 & 12.23 & 63.31 & 1.33 \\
\hline
\end{tabular}

Note. No. number of examinees

Table 2. Emergency workers

\begin{tabular}{lllll}
\hline No & Age & Years of employment & Sick leave & Days spent in hospital \\
\hline \multirow{2}{*}{54} & (Mean) & (Mean) & (Mean) & (Mean) \\
\hline
\end{tabular}

Note. No. number of examinees

The increase in sick leave days was contributed by two firemen as each of them stayed on sick leave over a year, but in the end, though firefighters' sick leave was longer, it did not statistically differ considerably from emergency workers, $p=.256, p>.05$.

In firefighters, correlation between years of employment and sick leave, as well as correlation between years of employment and days spent in hospital, has shown a mild positive result (see Figure 2, Figure 3).

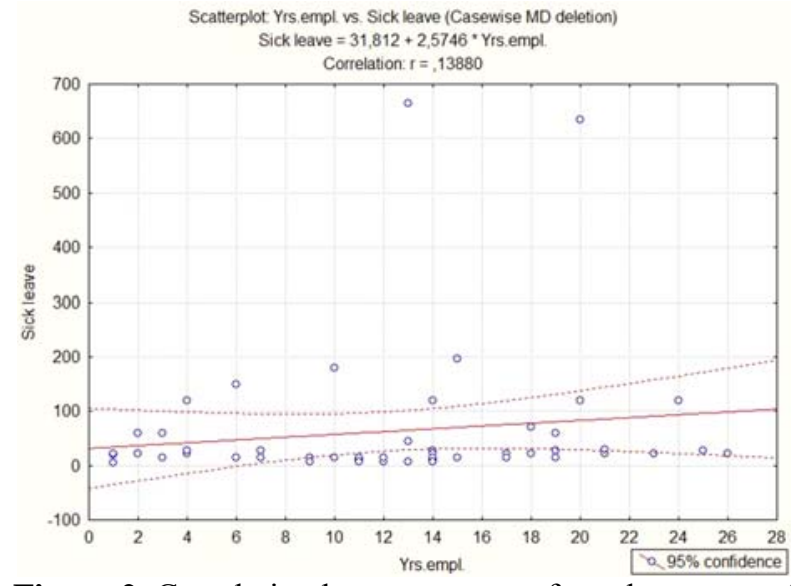

Figure 2. Correlation between years of employment and sick leave in firefighters

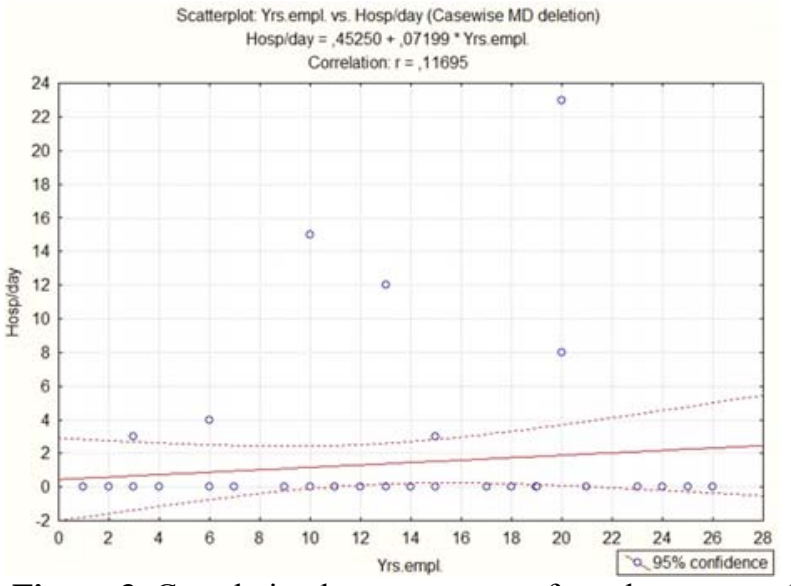

Figure 3. Correlation between years of employment and days spent in hospital in firefighters

\section{Discussion}

On the basis of the results a straightforward answer to the paper's title can be given that the activities of high professions do not lead to long hospital treatment. On the contrary, both groups of examinees show that the average hospital treatment is very short, particularly of emergency workers with practically no hospitalizations. Cautiousness is needed when making conclusions. Even, though the number of hospital days was low, almost half of all firefighters and emergency workers were injured. They continued to be treated at outpatient clinics for physical therapy in hospital centers.

Physical therapy was predominately needed because of muscle and tendon injuries, dislocated joints and extremity fractures.

Because firefighting requires good psychophysical abilities, they are tested on basic anthropological characteristics such as height and weight, the body fats, Vo2 (max.) - Astrand oxygen test, bench test - stamina test, or modifications as bicycle-ergometry, mobile line etc. ${ }^{[19]}$. Their augmented body weight increases muscular injury risks but also muscular 
endurance ${ }^{[20]}$. Therefore it is important for firefighters to keep fit by practicing the required exercises ${ }^{[21]}$. There are many programs, e. g. PHLAME health promotion programme, that are less expensive and reduce injuries and sick leave days ${ }^{[22]}$. Expertly programmed exercises are of high importance, are relatively hard and sometimes cause injuries, but they more than halve the risks of field injuries ${ }^{[23]}$. Some training academies use test such as Functional Movement Screen (FMS) which serve as predictors of injury status, and identifies the firefighters with increased injury risks ${ }^{[24]}$.

Since firefighters must undergo a combined training to be able to face the most difficult situations, a short high endurance and strength are needed but other time it is long time endurance. The short time endurance is achieved by anaerobic fosfagen training. It includes various training activities, repeatedly practiced at high intensity lasting 4 seconds-20 seconds. There are short sprints, a series of hops and jumps, circling training with intervals up to 20 seconds, as well as the specific situation exercises. Here heart frequency goes up to 190 beats per minute.

Another type of anaerobic training is attained by running $200 \mathrm{~m}-600 \mathrm{~m}$, circling trainings with working intervals up to 60 seconds, as well as training areas and situation exercises one minute to two minutes.

Long time endurance is achieved by aerobic training which increases ability for oxygen transfer. Practices of that kind may last over 60 minutes with maximum tempo strain of $60 \%-75 \%$, and heart frequency $150-170$ per minute.

It is important to develop strength in firefighters, which can be achieved through weight lifting, and explosive power, when after a jump one has to take off again, repetitive power (sit and reach test) etc.

It is important that fireman gain flexible, to be able to move the body and the limbs to a great extent. They must also gain agility to avoid danger by quick change of direction.

From the aspect of training conditioning one has to be familiar with dynamics and intensity of decompensation process (exhaustion, tiredness), compensation process (recovery, recuperation), super compensation process (gaining the body's maximal level) i.e. specific reaction of one's body because in the combine training process, it is best when the next training is time at the peak of super compensation wave (time for firefighter action, or sportsman competition).

Balance is one of the essential preconditions for the profession of firefighter. Firefighter's proprioceptive training on platform balancing is a good way to practice keeping balance. It is obvious that if one has phobias, of height or other fears, the elements of neurosis, the candidate is eliminated from this profession at the occupational medicine preliminary examination.

In Croatia a lot of attention is paid to firefighters' fitness by regular periodic tests at occupational medicine, resulting in an average of only 1.33 days of firemen's hospital treatments in the last decade.

That result can be consider "a chance result" irrespective of all activities which enhance firefighters' preparedness. When unforeseeable disasters, large scale fires etc. occur (which has not been the case in our county in the monitored period) the number of days of hospitalization and sick leave would be substantially increased. As mentioned in the introduction at the Kornati Islands, an eruptive fire resulted not only in hospitalization of the injured but also in the death of 12 firemen. These are situations where we are defenseless.

Overall, in their regular activities and standard interventions firefighters' number of days of hospital treatment was very low.

Emergency workers practically had no days of hospitalization due to work injuries, but both groups had sick leave. The firefighters' total number of sick leave days was higher because of two firemen of whom each was on sick leave almost 
two years. In both cases the problem was an injured knee.

Today, justification of a sick leave over a year is carefully scrutinized. Namely, while Croatian occupational medicine was in charge of sick leave was more than halved compared to the period when family physicians were in charge ${ }^{[25]}$.

Sickness certification is a complex task requiring multidisciplinary approach. It may cause a conflict between the physician and his patient. A complex assessment requires studying the functional status, mental abilities, but also the patient's social position. The general practitioner is often in agreement with the patient, even though the physician makes his assessment on the basis of the patient's condition while the patient makes a self-assessment regarding his job, on what he thinks he is unable to cope with.

There are few cases in which general practitioner declines certification for sick leave. The physician's personality, his attitude towards work and sick leave play an important role in assessing ability for work. Depending on one's own view and experience, a physicians' sickness certification causes a great burden, sometimes even a dilemma, while for some it makes no problem. But each physician as a professional will base his assessment on probable functional limits in regard to the work place that is to the assessment of medical factors rather than on somatic disorders claimed by patient. The major problem in assessing temporary disability is between general practitioners and specialists such as orthopedists and surgeons. It is most difficult to decide on temporary disability regarding work injury and occupational disease. So, in order to diminish the pressure on general practitioners, but also to decrease the number of unnecessarily lost working days Croatian Institute for Workers' Health Protection was founded, starting on January 1, 2008.

It lasted for two years. In 2011, sick leave certification in Croatia was again taken over by Family Medicine whose physicians by education, but also position (relation towards the patient; the physician being chosen depends on the patient) are not qualified as occupational medicine specialists to assess work ability. So again sick leave i.e. the total number of lost working days increased.

Normally, firefighters after six months and again after a year had to be reexamined by Disability Review Board since the stance of the Croatian Institute for Workers' Health Protection is that after a year a person is either cured or invalid which calls for retaining.

Because the firefighters are not patients of our occupational medicine surgery, we were allowed to study their files on work injuries and consequent treatment and had difficulty to assess the reasons for long sick leave of the two mentioned firefighters.

With such long sick leave one can think of the so called "sickness presenteeism" leading to absenteeism for which we have compiled specific scales "Rijeka Presenteeism Scale" and "Rijeka Absenteeism Scale" ${ }^{[26]}$. Rijeka Presenteeism Scale was used instead of the standard "Stanford Presenteeism Scale", as a modified scale to study positive presenteeism in our area. According to the Crombach's alpha test, Rijeka Presenteeism Scale was more reliable in our parts probably because of the language barrier and our people's way of thinking even though it was validation.

Shipyard workers who work on heights and bind themselves by firemen's safety belts, with the results showing that shipyard workers are positively oriented towards their jobs and working environment.

Though firefighters were not submitted to such tests but to other psychological tests, it is a well known fact that firefighters are positive and stable persons who often regardless of consequences do the utmost to save lives. In spite of that, "rental neurosis" may occur in some firefighters.

The injuries received during the process of work get compensation $100 \%$ of the wages during the sick leave. 
Also, there is a possibility that the person is interested in a long sick leave aware of hard training and conditioning ahead, which sometimes caused injuries in the past, so there is little motivation to go back to work, on other words, they lack positive presenteeism.

In our case emergency workers are employed by the County Emergency Medicine Institute which is not a part of Clinical Hospital Center, but also Clinical Hospital Center has its emergency service whose employees as well as those of Emergency Medicine Institute could be submitted to endurance and conditioning tests e.g. the nurses exposed to cytostatics ${ }^{[27]}$.

Each activity in medicine and hospital centers is specific so preventive measures are needed to assure personnel protection and safety.

\section{Conclusion}

The average of the days spent in hospital due to work injuries in high risk professions is low but it does not mean less expensive for hospital system. Namely, both groups of examinees (firefighters somewhat more) continue the treatment as outpatients because of physical therapy on hospital surgeries. The only solution is to prevent injuries which can be diminished by preventive conditioning programs, of programmed strength training at particular parts of body that are "vulnerable" and frequently prone to injuries. This can be attained by cooperation of modern occupational medicine and sports services and trainers which will surely result in decreasing injuries.

Looking generally, when injury occurs, it can be solved. It leads to the significant material expenses, what burdened hospital systems, i.e. the government, because hospitals in the Republic of Croatia are mostly governmental. In some medical systems, expenses of injury consequences fall on the private hospitals, private health insurances, employers, or directly on the "back" of injured workers.

Regardless of the medical system type of organization, this paper accentuate preventive measures, professional training and education on workplace, that securely reduce the number of injured workers in Croatia, as well as in other countries in the world. Well fit and skill worker is significantly less prone to the different type of injuries. The money invested on workers' training will be returned manifold.

When the Republic of Croatia was on the brink of joining the EU all regulations are being harmonized with EU directives and the field of medicine has been successfully updated ${ }^{[28]}$.

Especially now, as the member of EU, Croatia tries to be recognized as a region leader in preventive medicine, reducing hospital costs provoked by different types of unnecessary injuries.

\section{Competing interest}

There is no competing interest in this paper. The corresponding author has had the original text corrected in English at his own expense.

\section{Acknowledgements}

We thank Health and Safety services of Fire brigade Rijeka and the County Emergency Medicine Institute for their openness and cooperativeness, permission to use their data on work injury in the last 10-years period. 


\section{References}

[1] Lalić, H., Bukmir, L., Ferhatović, M. Simulation of working conditions by maximum work load on firefighters. Coll Antropol. 2007; 31(1): 153-8. PMid: 17598394.

[2] Lalić, H., Bukmir, L., Ferhatović, M. Examining psychic consequences in firefighters exposed to stress. Coll Antropol. 2007; 31(2): 451-5. PMid: 17847922.

[3] Jahnke, SA., Poston, WS., Haddock, CK. Obesity and incident injury among career firefighters in the central united states. Obesity (Silver Spring) 2013; Epub ahead of print. PMid: 23512940. http://dx.doi.org/10.1002/oby.20436

[4] Bos, J., Mol, E., Visser, B., Frings-Dresen, M. Risk of health complaints and diasbilities among Dutch firefighters. Int Arch Occup Environ Health. 2004; 77(6): 373-82. Pmid: 15338222.

[5] Britton, C., Ramirez, M., Lynch, CF., Torner, J., Peek-Asa, C. Risk of injury by job assigment among federal wildland firefighters, United States, 2003-2007. Int J Occup Environ Health. 2013; 19(2):77-84. PMid: 23684265. http://dx.doi.org/10.1179/20493967Y.0000000019

[6] Inansci, W., Guidotti, TL. Occupation-related burns: five year experience of an urban burn center. J Occup Med. 1987; 29(9):730-3. PMid: 3681505.

[7] Lalić, H. Could the Kornati islands firefighting tragedy have been avoided with better occupational medicine and safety? J Def Manag. 2012; 2: 104. http://dx. doi.org/10.4172/jdfm.1000104.

[8] Britton, C., Lynch, CF., Ramirez, M., Torner, J., Buresh, C., Peek-Asa, C. Epidemiology of injuries to wildland firefighters. Am J Emerg Med. 2013; 31(2): 339-45. PMid: 23158597. http:// dx.doi.org/10.1016/j.ajem.2012.08.032. Epub 2012 Nov 15.

[9] Miranda, AI., Martins, V., Cascao, P., Amorim, JH., Valente, J., Borrego, C., et al. Wildland smoke exposure values and exhaled breath indicators in firefighters. J Toxicol Environ Health A. 2012; 75(13-15): 831-43. PMid: 22788370. http://dx.doi.org/10.1080/15287394.2012.690686

[10] Donoughe, K., Whitestone, J., Gabler, HC. Analysis of firetruck crashes and associated firefighter injuries in the United States. Ann Adv Automot Med. 2012; 56: 69-76. PMid: 23169118

[11] Maguire, BJ., Smith, S. Injuries and fatalities among emergency medical technicians and paramedics in United States. Prehosp Disaster Med. 2013; 9: 1-7. PMid: 23659321 (Epub ahead of print).

[12] Lalić, H., Ferhatović, M., Dinko, J., Culinović, M. Hearing damage as a consequence of firefighters' professional exposure to noise. Acta Med Croatica. 2009; 63(2): 195-9.

[13] Kowalenko, T., Gates, D., Gillepsie, GL., Succop, P., Mentzel, TK. Prospective study of violence against ED workers. Am J Emerg Med. 2013; 31(1): 197-205. PMid: 23000325. http://dx.doi.org/10.1016/j.ajem.201207.010. Epub 2012 Sep 20.

[14] Kowalenko, T.m, Hauff, SR., Morden, PC., Smith, B. Development of data collection instrument for violent patient encounters against healthcare workers. West J Emerg Med. 2012; 13(5): 429-33. PMid: 23358263

http://dx.doi.org/10.5811/westjem.2011.12.6795

[15] Goniewicz, M., Wloszczak-Szubzda, A., Niemcewicz, M., Witt, M., Marciniak-Niemcewicz, A., Jarosz, MJ. Injuries caused by sharp instruments among healthcare workers - international and Polish perspectives. Ann Agric Environ Med. 2012; $19(3)$ : 523-7. PMid: 23020050.

[16] Maguire, BJ., Hunting, KL., Smith, GS., Levick, NR. Occupational fatalities in emergency medical services: a hidden crisis. Ann Emerg Med. 2002; 40(6): 625-32. PMid: 12447340.

[17] Reichard, AA., Jackson, LL. Occupational injuries among emergency responders. Am J Ind Med. 2010; 53(1):1-11. PMid: 19894221. http://dx.doi.org./10.002/ajim.20722.

[18] Maguire, BJ., Smith, S. Injuries and fatalities among emergency medical technicians and paramedics in the United States. Prehosp Disaster Med. 2013; 9: 1-7. Epub ahead of print. PMid: 23659321.

[19] Calavalle, AR., Sisti, D., Mennelli, G., Andolina, G., Del Sal, M., Rocchi, MB., et al. A simple method to analyze overall individual physical fitness in firefighters. J Strenght Cond Res. 2013; 27(3): 769-75. PMid: 22706575. http:// dx.doi.org/10.1519/JSC.ObO13e3182600554

[20] Mayer, JM., Nuzzo, JL., Chen, R., Quillen, WS., Verna, JL., Miro, R., et al. The impact of obesity on back and core muscular endurance in firefightetrs. J Obes. 2012; 2012: 729283. PMiD: 23213491. http://dx.doi.org/10.155/2012/729283. Epub 2012 Nov 19.

[21] Mayer, JM., Nuzzo, JL., Dagenais, S. Use of participants focus groups to identify barriers and facilitators to worksite exercise therapy adherence in randomized controlled trials involving firefighters. Patient Prefer Adherence. 2013; 7: 207-15. PMid: 23515182. http://dx.doi.org./10.2147/PPA.s42507. Epub 2013 Mar 13. 
[22] Kuehl, KS., Elliot, DL., Goldberg, L., Moe, EL., Perrier, E., Smith, J. Economic benefit of the PHLAME wellness programme on firefighter injury. Occup Med (Lond). 2013; 63(3): 203-9. PMid: 23416849. http://dx.doi.org./10.1093/occmed/kqs232. Epub 2013 Feb 15.

[23] Jahnke, SA., Poston, WS., Haddock, CK, Jitnarin, N. Injury among a population based sample of career firefighters in the central USA. Inj Prev. 2013; Epub ahead of print. PMid: 23504995.

[24] Butler, RJ., Contreras, M., Burton, LC., Plisky, PJ., Goode, A., Kiesel, K. Modifiable risk factors predict injuries in firefighters training academies. Work. 2013; Epub ahead of print. PMid:23324700

[25] Lalić, H. Occupational medicine in taking over work injuries from family practice - a one year follow up. Coll Antropol. 2009; 33(3): 939-43. PMid: 19860129

[26] Lalić, H., Hromin, M. Presenteeism towards absenteeism: manual work versus sedentary work, private versus governmental - a Croatian review. Coll. Antropol. 2012; 36(1): 111-6. PMid: 22816206.

[27] Lalić, H. Importance of using micronucleus test for hospital personnel exposed to cystotatics - Croatian study. J Hosp Adm. 2013; 2(1): 40-8. http://dx.doi.org./10.5430/jha.v2n1p40.

[28] Lalić, H. International Occupational Medicine: Croatia. Occup Med (Lond). 2008; 58(5): 376. PMid: 18676428 http://dx.doi.org./10.1093/occmed/kqn060 